\title{
Subaortic course of innominate vein
}

INSERM

\section{Source}

INSERM. (1999). Orphanet: an online rare disease and orphan drug data base. Subaortic course of innominate vein. ORPHA:99113

Subaortic course of innominate vein is a rare congential anomaly of the great veins characterized by an anomalous course of the left brachiocephalic vein, passing from left to right below the aortic arch and entering the superior vena cava below the orifice of the azygos vein. Patients are frequently asymptomatic and diagnosed incidentally on imaging studies. Other cardiac malformations may be associated. 